Jurnal Bimbingan dan Konseling Ar-Rahman
Volume 7, Nomor 1, Tahun 2021
Tersedia Online: http://ojs.uniska.ac.id/index.php/BKA
e-ISSN 2477-6300

\title{
MENINGKATKAN MOTIVASI BELAJAR DENGAN LAYANAN KONSELING KELOMPOK TEKNIK SELF-CONCEPT TERHADAP SISWA PERINGKAT AKHIR KELAS VIII DI SMP NEGERI 1 BANJARMASIN
}

\author{
Muzdalifah ${ }^{1}$, Kasypul Anwar, Nurmiati \\ Universitas Islam Kalimantan Muhammad Arsyad Al Banjari Banjamasin \\ ${ }^{1}$ muzdalifah605@gmail.com
}

\begin{abstract}
ABSTRAK
Penelitian ini bertujuan untuk mengetahui:(1)motivasi belajar siswa peringkat akhir kelas VIII di SMP Negeri 1 Banjarmasin sebelum diberikan layanan (2)motivasi belajar siswa peringkat akhir kelas VIII di SMP Negeri 1 Banjarmasin sesudah diberikan layanan (3)efektivitas layanan konseling kelompok teknik self concept untuk meningkatkan motivasi belajar siswa peringkat akhir kelas VIII di SMP Negeri 1 Banjarmasin. Penelitian kuantitatif ini bersifat eksperimen, one group pretest-posstest design dengan purposive sampling yaitu 8 siswa peringkat akhir. Metode pengumpulan data menggunakan observasi dan angket motivasi belajar. Analisis data menggunakan statistik deskriptif dan uji wilcoxon. Hasil penelitian menunjukkan bahwa: (1) motivasi belajar siswa peringkat akhir kelas VIII di SMP Negeri 1 Banjarmasin sebelum diberikan layanan berada dalam kategori rendah dengan skor rata-rata 127,75 (2) motivasi belajar siswa peringkat akhir kelas VIII di SMP Negeri 1 Banjarmasin sesudah diberikan layanan berada dalam kategori tinggi dengan skor rata-rata 177,8 (3)layanan konseling kelompok teknik self concept untuk meningkatkan motivasi belajar siswa peringkat akhir kelas VIII di SMP Negeri 1 Banjarmasin adalah efektif, dilihat dari perbedaan selisih rata-rata sebesar 51,25 . Uji wilcoxon juga menunjukkan nilai $Z$ sebesar -2.521 dengan pvalue (Asymp Sig 2 tailed) 0,012 dimana kurang dari batas kritis penelitian $a=0,05$ yang berarti Ha diterima dan terdapat perbedaan bermakna antara pretest-posttest.
\end{abstract}

Kata Kunci: Motivasi; Konsep Diri; Siswa Peringkat Akhir

\begin{abstract}
This study aims to find out: (1) students' learning motivation in the final grade VIII class at SMP Negeri 1 Banjarmasin before being given a service (2) student learning motivation in the final class VIII grade at SMP Negeri 1 Banjarmasin after being given services (3) the effectiveness of technical group counseling services self-concept to improve student motivation in the final grade VIII grade at SMP Negeri 1 Banjarmasin. This quantitative research is experimental, one group pretest-posstest design with purposive sampling that is 8 students ranked last. The data collection method uses observation and learning motivation questionnaire. Data analysis using descriptive statistics and Wilcoxon test. The results showed that: (1) the learning motivation of students in the final grade VIII at SMP Negeri 1 Banjarmasin before being given services was in the low category with an average score of 127.75 (2) the learning motivation of students at the end of class VIII in SMP Negeri 1 Banjarmasin after being given a service that is in the high category with an average score of 177.8 (3) self-concept technique group counseling services to increase students' learning motivation in the final grade VIII grade at SMP Negeri 1 Banjarmasin is effective, seen from the difference in the average of 5125 years old. Wilcoxon test also showed a $Z$ value of -2.521 with pvalue (Asymp Sig 2 tailed) 0.012 which is less than the critical limit of research $a=0.05$ which means $\mathrm{Ha}$ is accepted and there are significant differences between pretestposttest.
\end{abstract}

Keywords: Motivation; Self-Concept; Underachiever Student 
Muzdalifah, Kasypul Anwar, Nurmiati Jurnal Bimbingan dan Konseling Ar-Rahman Volume 7, Nomor 1, Tahun 2021

e-ISSN 2477-6300

\section{PENDAHULUAN}

Manusia merupakan makhluk yang unik dan berkembang menjadi organisme yang segar dan siap untuk belajar mengenal dirinya sendiri. Mengenal diri yang di maksud adalah self concept Self concept merupakan bagian penting dalam perkembangan kepribadian. Seperti yang dikemukakan oleh Rogers bahwa konsep kepribadian yang paling utama dalam diri. Diri (self) berisi ide-ide persepsi dan nilai-nilai yang mencakup identitas diri yakni karakteristik personal, pengalaman, peran dan status social (Thalib, 2010). Self concept akan menentukan siapa seseorang itu dalam kenyataannya, siapa seseorang itu menurut pikirannya, dan akan menentukan bisa menjadi apa seseorang itu menurut pikirannya sendiri. Self concept berkembang sesuai dengan pertumbuhan yang dialami oleh individu baik itu dari fisik maupun dari mental. Oleh karena itu apabila perkembangan seorang anak yang normal, maka self concept yang dimilikinya akan terus terbentuk dari mulai dirinya masih kecil dan terus berganti dengan self concept yang baru dan sejalan dengan pengalamannya.

Selain itu sejumlah ahli psikologi dan pendidikan juga berkeyakinan bahwa self concept dan prestasi belajar mempunyai hubungan yang erat. Nylor dalam Desmita misalnya, mengemukakan bahwa banyak pendidikan yang membuktikan hubungan positif yang kuat antara self concept positif dengan prestasi belajar di sekolah.Siswa yang memiliki self concept positif memperlihatkan prestasi yang baik disekolah, atau siswa yang berprestasi tinggi disekolah memiliki penilaian diri yang tinggi, serta menunjukan hubungan antar pribadi yang positif pula (Desmita, 2009).

'Siswa belajar karena didorong oleh keinginan mentalnya. Kekuatan mental ini berupa keinginan, perhatian dan kemauan atau cita-cita. Kekuatan mental tersebut tergolong rendah atau tinggi. Siswa dalam mengikuti proses belajar tentunya mempunyai motivasi belajar. Motivasi ini bukan saja penting karena menjadi faktor penyebab belajar, namun juga memperlancar belajar dana hasil belajar. Siswa yang mempunyai motivasi belajar tinggi memungkinkan akan memperoleh hasil belajar yang tinggi pula, artinya semakin tinggi motivasinya, semakin tinggi intensitas usaha dan upaya yang dilakukan maka semakin tinggi hasil belajar yang diperolehnya.

Siswa yang memang memiliki motivasi tinggi akan melakukan berbagai upaya atau usaha untuk meningkatkan keberhasilan sebagaimana yang diharapkan. Disamping itu motivasi juga menopang upaya-upaya dan menjaga agar proses belajar siswa tetap jalan. Hal inilah yang menjadikan siswa gigih dalam belajar. Sesuai dengan (Djaali, 2011) yang menyebutkan bahwa belajar akan optimal, jika adanya motivasi dalam belajar, semakin tepat motivasi belajar yang diberikan maka akan semakin berhasil pula pelajaran itu. Jadi motivasi akan senantiasa menentukan usaha belajar bagi siswa. Motivasi belajar dapat timbul karena faktor intrinsik, berupa hasrat dan keinginan berhasil dan dorongan kebutuhan belajar, harapan akan citacita. Sedangkan faktor ekstrinsik berupa adanya penghargaan, lingkungan belajar yang kondusif, dan kegiatan belajar yang menarik. .(Sardiman, 2012)

Seorang guru lebih mungkin mempengaruhi self concept terpelajar pada diri seorang siswa ketimbang terhadap self concept sosialnya yang sangat lebih dipengaruhi oleh teman-temannya. Namun tanggung jawab guru pembimbing adalah membantu peserta didik (siswa) agar dapat mengembangkan potensi yang dimilikinya secara maksimal.Potensi peserta didik yang harus dikembangkan bukan hanya menyangkut masalah kecerdasan dan keterampilan, melainkan menyangkut seluruh aspek kepribadian serta self concept dan motivasi belajarnya. Salah satu peran yang dijalankan oleh guru yaitu sebagai pembimbing dan untuk menjadi pembimbing yang baik guru harus memiliki pemahaman tentang anak yang sedang dibimbingnya.

Penelitian Asih (2015) mengenai tingkat motivasi belajar siswa yang dilakukan di SMPN 15 Yogyakarta menyebutkan bahwa motivasi instrinsik yang dimiliki siswa SMPN 15 Yogayakarta adalah minat yang bersalah dari diri mereka sendiri, sedangkan ekstrinsik mereka adalah adnya pemberian reward dan remidi untuk perbaikan nilai, faktor yang mempengaruhi motivasi belajar mereka selain minat adalah kurangnya fasilitas dan ajakan teman sepermainan yang membawa pengaruh yang negative, upaya yang dilakukan sekolah untuk meningkatkan motivasi belajar siswa adalah memberikan penghargaan kepada siswa yang berprestasi, menang dalam perlombaan dan memberikan pujian terhadap siswa yang berhasil menjawab pertanyaan.

Selaras dengan penelitian tersebut berdasarkan studi pendahuluan yang dilakukan di SMP Negeri 1 Banjarmasin peneliti mencoba mencari tahu bagaimana kondisi motivasi belajar siswa kelas VIII. Sehingga peneliti menemukan masih adanya siswa disana juga memiliki indikasi memiliki motivasi belajar yang rendah, terutama untuk siswa peringkat akhir. Diantaranya adalah terlihat siswa yang enggan belajar dan tidak bersemangat dalam menerima pelajaran di kelas. Sebagian siswa juga belum aktif dalam 
Muzdalifah, Kasypul Anwar, Nurmiati

Jurnal Bimbingan dan Konseling Ar-Rahman

Volume 7, Nomor 1, Tahun 2021

e-ISSN 2477-6300

mengerjakan tugas dan soal latihan yang diberikan. Juga ditemukannya sebagian siswa peringkat akhir yang bersikap pesimis/tidak yakin dengan kemampuan intelektualnya. Selain itu menurut guru bidang studi dan walikelas mengenai siswa yang memiliki motivasi belajar rendah dapat dilihat dari beberapa siswa yang terlihat bermalas-malasan saat proses belajar berlangsung bahkan ada siswa yang lebih tertarik bermain ponsel saat proses belajar berlangsung.

Penelitian ini diwujudkan sebagai salah satu bentuk usaha untuk meningkatkan motivasi belajar siswa peringkat akhir yang kemudian disebut sebagai siswa, Siswa peringkat akhir yang dimaksud adalah masing-masing 2-3 orang siswa yang menduduki peringkat 1 dan 3 dari akhir pada saat kelas VII yang sekarang menduduki kelas VIII A, D dan E. Selain itu juga sebagai referensi untuk penelitian selanjutnya. Karena seperti yang diketahui bahwa meningkatkan motivasi belajar adalah tugas bersama, bukan hanya guru atau pembimbing saja.

Pelaksanaan layanan yang dilakukan oleh sekolah untuk berusaha meningkatkan motivasi belajar secara general tampaknya masih menyisakan pekerjaan bagi mereka sebagai guru pembimbing tentang bagaimana cara yang lebih efektif untuk menjadikan siswa mampu mencapai motivasi belajar yang optimal. Oleh karena itu peneliti memutuskan untuk menggunakan layanan konseling kelompok yang mana konseling kelompok adalah salah satu layanan yang sangat mudah digunakan karena layanan ini bersifat pengentasan terhadap permasalahan yang sedang dialami oleh anggota kelompoknya terlebih siswa peringkat akhir yang memiliki permasalahan dalam bidang belajar. Konseling kelompok yang akan dilakukan bertujuan agar mereka memiliki motivasi belajar yang tinggi.

Untuk membantu siswa mendapatkan karakter maka peneliti memutuskan untuk menggunakan teknik Self Concept, karena semakin baik self concept seseorang maka akan semakin baik pula tingkat kehidupannya. Bersamaan dengan ini apabila memiliki self concept yang positif akan memiliki motivasi belajar yang tinggi sedangkan yang memiliki self concept yang negatif cenderung memiliki motivasi belajar yang rendah. Dapat terlihat juga bahwa rendahnya motivasi belajar pada siswa, tentu akan menghambat proses belajar dalam kelas. Sehingga peneliti tertarik untuk melakukan penelitian yang mendalam tentang motivasi belajar siswa SMP dan memfokuskan untuk melakukan penelitian dengan judul "Meningkatkan Motivasi Belajar dengan Layanan Konseling Kelompok Teknik Self Concept terhadap Siswa Peringkat Akhir Kelas VIII di SMP Negeri 1 Banjarmasin.

\section{METODE}

Metode penelitian yang digunakan dalam penelitian ini adalah penelitian kuantitatif menggunakan studi eksperimen. Metode ini digunakan atas dasar pertimbangan bahwa bersifat experimental, yaitu mencobakan sesuatu untuk mencari pengaruh atau akibat dari suatu perlakuan atau treatment. (Sugiyono, 2016) mengatakan bahwa: "penelitian eksperimen dapat diartikan sebagai metode penelitian yang digunakan untuk mencari pengaruh terhadap kondisi yang terkendalikan".

Adapun gambaran singkat prosedur penelitian adalah : 1. Mengidentifikasi variabel; 2. Mengembangkan dan menemukan instrument; 3 . Menyebarkan dan mengadministrasikan instrument (pretest-posttest); 4. Menganalisis data dan menulis laporan penelitian.

Populasi dalam penelitian ini adalah kelas VIII tahun ajaran 2019-2020 yaitu dengan nilai akademik raport dilihat dari kelas VII untuk menentukan masuk tidaknya ia kedalam kualifikasi siswa peringkat akhir dengan motivasi belajar rendah. Secara spesifik, teknik sampling yang digunakan adalah teknik nonprobabilitas, dimana setiap sampel tidak memiliki kesempatan yang sama untuk dipilih yakni dengan menggunakan pengambilan sampel secara bertujuan (purposive sampling). Dari jumlah populasi maka sampel dalam penelitian ini berjumlah 8 orang siswa peringkat akhir kelas VIII. Yang telah memenuhi kualifikasi dari nilai IPK raport kelas VII sebelumnya.

Teknik dan isntrumen penelitian adalah observasi dan kuisioner, Adapun pada penelitian ini menggunakan skala Likert yang dibuat dalam bentuk selalu, sering, kadang-kadang dan tidak pernah. Terdiri dari 56 item pertanyaan skala motivasi belajar.

\section{HASIL DAN PEMBAHASAN}

Hasil pengisian skala motivasi belajar 8 orang siswa peringkat akhir sebagai responden sebelum di berikan layanan konseling kelompok teknik self concept dapat dilihat pada tabel dibawah ini. 
Muzdalifah, Kasypul Anwar, Nurmiati

Jurnal Bimbingan dan Konseling Ar-Rahman

Volume 7, Nomor 1, Tahun 2021

e-ISSN 2477-6300

Tabel 2. Skor Pretest Motivasi Belajar Siswa Peringkat Akhir kelas VIII di SMPN 1 Banjarmasin

\begin{tabular}{clccc}
\hline No & Nama & Skor & Presentase & Keterangan \\
\hline 1 & R1 & 117 & $52,23 \%$ & Rendah \\
2 & R2 & 129 & $57,5 \%$ & Rendah \\
3 & R3 & 154 & $68,75 \%$ & Tinggi \\
4 & R4 & 109 & $48,66 \%$ & Rendah \\
5 & R5 & 127 & $56,6 \%$ & Rendah \\
6 & R6 & 137 & $61,1 \%$ & Rendah \\
7 & R7 & 111 & $49,5 \%$ & Rendah \\
8 & R8 & 138 & $61,6 \%$ & Rendah \\
\hline \multicolumn{2}{c}{ Rata-Rata Skor } & $\mathbf{1 2 7 , 7 5}$ & $\mathbf{5 7 , 0 3 \%}$ & Rendah \\
\hline
\end{tabular}

Dari 8 orang responden, mennduduki kategori rendah, sedangkan 1 orang menduduki kategori tinggi.Berdasarkan penjelasan hasil penelitian pada pretest sebelum dilakukan layanan konseling kelompok teknik self concept, maka dapat diketahui dari 8 responden, 7 responden menduduki kategori rendah, sedangkan 1 responden menduduki kategori tinggi. Nilai skor interval rata-rata dari 8 orang tersebut adalah 127,75 dan presentase nya $57,03 \%$. Sehingga dapat disimpulkan gambaran secara umum tentang motivasi belajar siswa peringkat akhir kelas VIII di SMP Negeri 1 Banjarmasin sebelum diberikan layanan konseling diketahui hasil rata-rata dari 8 responden sebanyak 127,75 dengan presentase $(57,03 \%)$ adalah rendah.

Keadaan yang terjadi di SMP Negeri 1 Banjarmasin dan dialami oleh siswa tentunya didasari oleh berbagai macam faktor yang menyebabkan mereka memiliki motivasi belajar rendah. Yang pertama adalah, kurangnya perhatian guru terhadap siswanya. Guru di sekolah bukan hanya berfungsi sebagai pendidik saja namun juga sebagai motivator handal bagi siswa yang mampu membangkitkan semangat belajar mereka. Peran guru dalam memotivasi siswa sangat penting, khususnya bagi siswa yang malas belajar dan bermasalah seperti beberapa siswa peringkat akhir sebagaimana sampel penelitian. Sedikit banyaknya motivasi yang diberikan akan melekat di dalam hati siswa. Bahkan fakta membuktikan bahwa guru yang lebih dekat dengan siswa, sering berinteraksi dengan mereka akan lebih disukai oleh mereka.

Kemudian lemahnya motivasi belajar dalam diri siswa itu sendiri merupakan faktor utama yang dialami oleh kebanyakan siswa, sehingga menyebabkan kurangnya minat mereka dalam belajar dan menghabiskan waktu sekolah bertahun-tahun dengan sia-sia. Siswa yang tidak memiliki impian dan cita-cita yang jelas, siswa yang tidak percaya diri dan merasa dirinya tidak pintar atau secerdas teman lainnya yang menganggap tujuan akhir dari sekolah adalah untuk bekerja saja menyebabkan siswa tidak serius dalam hal pembelajaran sehingga membuat mereka menjadikan pendidikan hanya sebatas formalitas semata.

Tercapainya tujuan penelitian mulai terlihat dimana peserta didik sangat berantusias dalam proses pemberian layanan. Peserta didik mulai melakukan terapi dalam mengatasi pola pikir mereka sendiri. Setelah pemberian layanan selesai peserta didik juga antusias dalam mengungkapkan ide dan gagasanya, adanya interaksi yang baik antara pemimpin kelompok dan peserta didik sehingga peserta didik saling memberikan pendapat dan saran ketika diminta pendapat. Ketika kegiatan akan berakhir peserta didik saling bergantian untuk menyimpulkan pemahaman materi dan perubahan pola pikir yang mereka dapatkan.

Hasil pengisian skala motivasi belajar 8 orang siswa peringkat akhir sebagai responden sesudah diberikan layanan konseling kelompok teknik self concept terhadap siswa peringkat akhir kelas VIII di SMP Negeri 1 Banjarmasin menunjukkan bahwa 7 menduduki kategori tinggi dan 1 orang menduduki kategori sangat tinggi. Hal ini bisa dilihat pada tabel 2 .

Tabel 3 kemudian menjelaskan perbandingan skor dan presentase jawaban angket motivasi belajar yang diisi 8 orang responden sebelum dan sesudah diberikan layanan konseling kelompok teknik Self Concept. 
Muzdalifah, Kasypul Anwar, Nurmiati

Jurnal Bimbingan dan Konseling Ar-Rahman

Volume 7, Nomor 1, Tahun 2021

e-ISSN 2477-6300

Tabel 2. Skor Motivasi Belajar Siswa Peringkat Akhir kelas VIII di SMP Negeri 1 Banjarmasin

\begin{tabular}{llccc}
\hline No & Nama & Skor & Presentase & Keterangan \\
\hline 1 & R1 & 179 & $79,9 \%$ & Tinggi \\
2 & R2 & 173 & $77,2 \%$ & Tinggi \\
3 & R3 & 202 & $90,1 \%$ & SangatTinggi \\
4 & R4 & 176 & $78,5 \%$ & Tinggi \\
5 & R5 & 180 & $80,3 \%$ & Tinggi \\
6 & R6 & 142 & $63,4 \%$ & Tinggi \\
7 & R7 & 169 & $75,4 \%$ & Tinggi \\
8 & R8 & 202 & $90,1 \%$ & Tinggi \\
\hline \multicolumn{2}{c}{ Rata-Rata Skor } & $\mathbf{1 7 7 , 8}$ & $\mathbf{7 9 , 4 \%}$ & Tinggi \\
\hline
\end{tabular}

Tabel 3. Hasil Analisis Statistik Deskriptif Pretest-Posttest (Sebelum dan Sesudah)

\begin{tabular}{cccccccc}
\hline \multirow{2}{*}{ No } & \multirow{2}{*}{ Nama } & \multicolumn{2}{c}{ Pretest } & \multicolumn{2}{c}{ Posttest } & \multicolumn{2}{c}{ Gain (d) } \\
\cline { 3 - 8 } & & Skor & Presentase & Skor & Presentase & Skor & Presentase \\
\hline 1 & R1 & 117 & $52,23 \%$ & 179 & $79,9 \%$ & 62 & $27,7 \%$ \\
2 & R2 & 129 & $57,5 \%$ & 173 & $77,2 \%$ & 44 & $19,7 \%$ \\
3 & R3 & 154 & $68,75 \%$ & 202 & $90,1 \%$ & 48 & $32,9 \%$ \\
4 & R4 & 109 & $48,66 \%$ & 176 & $78,5 \%$ & 67 & $29,9 \%$ \\
5 & R5 & 127 & $56,6 \%$ & 180 & $80,3 \%$ & 63 & $23,7 \%$ \\
6 & R6 & 137 & $61,1 \%$ & 142 & $63,4 \%$ & 4 & $2,3 \%$ \\
7 & R7 & 111 & $49,5 \%$ & 169 & $75,4 \%$ & 58 & $25,9 \%$ \\
8 & R8 & 138 & $61,6 \%$ & 202 & $90,1 \%$ & 64 & $28,5 \%$ \\
\hline \multicolumn{2}{l}{ Rata-Rata } & $\mathbf{1 2 7 , 7 5}$ & $\mathbf{5 7 , 0 3 \%}$ & $\mathbf{1 7 7 , 8}$ & $\mathbf{7 9 , 4 \%}$ & $\mathbf{5 1 , 2 5}$ & $\mathbf{2 2 , 8 \%}$ \\
\hline
\end{tabular}

Hasil analisis sebelum dan sesudah pada skor motivasi belajar siswa peringkat akhir terdapat perbedaan yang signifikan. R1 misalnya dengan nilai skor $117(52,23 \%)$ sebelum diberikan treatment, meningkat menjadi 179 (79,9\%). R2 dengan skor 129 (57,5\%), meningkat menjadi 173 $(77,2 \%)$. R3 dengan skor $154(68,75 \%)$ meningkat menjadi $202(90,1 \%)$. R4 dengan skor $109(48,66)$ meningkat menjadi $176(78,5 \%)$. R5 dengan skor $127(56,6 \%)$ meningkat menjadi $180(80,3 \%)$. R6 dengan skor $137(61,1 \%)$ meningkat menjadi 142 $(63,4 \%)$. R7 dengan skor $111(49,5 \%)$ meningkat menjadi 169 (75,4\%). R8 dengan skor $138(61,6 \%)$ eningkat menjadi $202(90,1 \%)$. Dengan rata-rata selisih $22,8 \%$, tersebut dinilai sebagai peningkatan skor dan presentase.

Hasil analisis statistik deskriptif tentang tingkat motivasi belajar siswa peringkat akhir kelas VIII di SMP Negeri 1 Banjarmasin sebelum dan sesudah diberikan treatmen menyimpulkan bahwa antara tingkat motivasi belajar siswa terdapat perbedaan antara sebelum dan sesudah diberikan perlakuan, yang mana ternyata hasil angket sesudah diberikan treatment lebih tinggi daripada sebelum diberikan treatmen.

Statistik deskriptif juga dihitung menggunakan SPSS versi 23 oleh peneliti, hasilnya adalah sebagai berikut.

Tabel 4. Hasil Statistik Deskriptif

\begin{tabular}{cccccc}
\hline & $\boldsymbol{N}$ & Mean & Std. Deviation & Minimum & Maximum \\
\hline Pretest & 8 & 127,75 & 15,257 & 109 & 154 \\
Posttest & 8 & 177,88 & 19,134 & 142 & 202 \\
\hline
\end{tabular}

Yaitu dengan jumlah responden ( $\mathrm{N}=8$ ), dengan rata-rata pretest 127,75 dan posttest 177,88. Skor jawaban terendah pretest 109 dan tertinggi 154 serta jawaban terendah posstest 142 dan tertinggi 202.

Penelitian ini dilakukan untuk mengetahui perbedaan tingkat motivai belajar siswa peringkat 
Muzdalifah, Kasypul Anwar, Nurmiati Jurnal Bimbingan dan Konseling Ar-Rahman Volume 7, Nomor 1, Tahun 2021

e-ISSN 2477-6300

akhir kelas VIII di SMP Negeri 1 Banjarmasin sebelum dan diberikan perlakuan yaitu layanan konseling kelompok teknik Self Concept. Sampel yang digunakan dalam penelitian sejumlah 8 orang. Kemudian diberikan pengujian terhadap motivasi belajarnya dengan menggunakan uji Wilcoxon Signed Rank. Berikut adalah data penelitian:

Tabel 5. Hasil Skor Jawaban Angket Responden

\begin{tabular}{cccc}
\hline Subjek & Pret Test & Post Test & Gain $(\boldsymbol{d})$ \\
\hline R1 & 117 & 179 & 62 \\
R2 & 129 & 173 & 44 \\
R3 & 154 & 202 & 48 \\
R4 & 109 & 176 & 67 \\
R5 & 127 & 180 & 63 \\
R6 & 137 & 142 & 4 \\
R7 & 111 & 169 & 58 \\
R8 & 138 & 202 & 64 \\
\hline$\sum$ & $\mathbf{1 . 0 2 2}$ & $\mathbf{1 . 4 2 3}$ & $\mathbf{4 1 0}$ \\
\hline
\end{tabular}

Dari data diatas kita menggunakan uji non-parametrik terhadap dua sampel yang berpasangan. Pada penelitian ini nilai Pretest = sebelum dan Posttest $=$ sesudah. Dengan hipotesis sebagai berikut :

Ha : Penggunaan layanan konseling kelompok dengan teknik self-concept dapat meningkatkan motivasi belajar siswa kelas VIII peringkat akhir di SMP Negeri 1 Banjarmasin.

Ho : Penggunaan layanan konseling kelompok dengan teknik self-concept tidak dapat meningkatkan motivasi belajar siswa kelas VIII peringkat akhir di SMP Negeri 1 Banjarmasin.

Jika $\mathrm{Z}$ hitung $<\mathrm{Z}$ tabel atau nilai sig $>$ 0,05, maka Ho diterima. Jika $\mathrm{Z}$ hitung $>\mathrm{Z}$ tabel atau nilai sig $<0,05$ maka Ho ditolak dan $\mathrm{Ha}$ diterima. Berikut adalah hasil perhitungan dari uji Wilcoxon dengan bantuan SPSS versi 23.

Tabel 5. Hasil Uji Wilcoxon

\begin{tabular}{lc}
\hline & Post test - pretest \\
\hline $\mathrm{Z}$ & $-2,521$ \\
Asymp. Sig. (2-tailed) & 0,012 \\
\hline $\mathrm{b}=$ Based on negative ranks
\end{tabular}

Berdasarkan hasil dari perhitungannya dengan Wilcoxon Signed Ranks, maka nilai Z yang didapat sebesar -2.521 dengan $p$ value (Asymp. Sig 2 tailed) sebesar 0,012 dimana kurang dari batas kritis penelitian $a=0,05, \mathrm{Ha}$ atau hipotesis alternatif diterima yang berarti terdapat perbedaan bermakna antara pretest dan posttest.

Peningkatan motivasi belajar siswa peringkat akhir juga dijelaskan dalam analisis data penelitian bahwa setelah perlakuan terdapat peningkatan pada skornya. Dengan diberikannya layanan konseling kelompok teknik Self Concept memberikan dampak positif pada siswa peringkat akhir. Diketahui bahwa $p$ value uji wilcoxon tersebut lebih kecil $a=0,05$ sehingga dapat disimpulkan terdapat perbedaan motivasi belajar siswa peringkat akhir, sebelum dan setelah diberikan layanan konseling kelompok.

\section{PENUTUP}

Penelitian yang telah dilakukan dapat ditarik kesimpulan bahwa motivasi belajar 8 orang siswa peringkat akhir sebagai responden sebelum di berikan layanan konseling kelompok teknik self concept yaitu dari 8 orang responden, 7 orang menduduki kategori rendah, sedangkan 1 orang menduduki kategori tinggi. Nilai skor interval ratarata dari 8 orang tersebut adalah 127,75 dengan presentase $(57,03 \%)$ dalam keterangan adalah rendah. Motivasi belajar 8 orang siswa peringkat akhir sebagai responden sesudah diberikan layanan konseling kelompok teknik self concept terhadap siswa peringkat akhir kelas VIII di SMP Negeri 1 Banjarmasin menunjukkan bahwa 7 menduduki kategori tinggi dan 1 orang menduduki kategori sangat tinggi. Dengan nilai skor interval rata-rata dari 8 orang tersebut adalah 177,8 dengan presentase $(79,4 \%)$ dalam keterangan adalah tinggi.

Hasil analisis sebelum dan sesudah pada skor motivasi belajar siswa peringkat akhir terdapat perbedaan yang signifikan. Dengan ratarata selisih $22,8 \%$, tersebut dinilai sebagai peningkatan skor dan presentase.Berdasarkan hasil dari perhitungannya dengan Wilcoxon Signed 
Muzdalifah, Kasypul Anwar, Nurmiati

Jurnal Bimbingan dan Konseling Ar-Rahman

Volume 7, Nomor 1, Tahun 2021

e-ISSN 2477-6300

Ranks, maka nilai $\mathrm{Z}$ yang didapat sebesar -2.521 dengan $p$ value (Asymp. Sig 2 tailed) sebesar 0,012 dimana kurang dari batas kritis penelitian $a=0,05$, $\mathrm{Ha}$ atau hipotesis alternatif diterima yang berarti terdapat perbedaan bermakna antara pretest dan posttest.

\section{REFERENSI}

Alvin, H. (1999). Gaya Kelekatan dan Konsep Diri. Jurnal Psikologi, 1, 7-9.

Alwisol. (2014). Psikologi Kepribadian Edisi revisi. Malang: UMM Press.

Arikunto. (2010). Prosedur Penelitian. jakarta: Rineka Cipta.

Burns. (2002). Konsep Diri (Teori Pengukuran, Perkembangan dan Perilaku). Jakarta: Arcan.

D.K, S. (2008). Pengantar Pelaksanaan Bimbingan dan Konseling di Sekolah dan Madrasah. Jakarta: Rineka Cipta.

Dariyo. (n.d.). Psikologi Perkembangan. 2007.

Desmita. (2009). Psikologi Perkembangan Peserta Didik. Bandung: Remaja Rosakarya.

Dimiyati. (2006). Belajar dan Pembelajaran. Jakarta: Rineka Cipta.

Djaali. (2011). Psikologi Pendidikan. Jakarta: Bumi Aksara.

Farasti, S., \& Rangka, I. B. (2016). Prosedur Layanan Bimbingan dan Konseling Kelompok. Bandung: Mujahid Press.

Fitri, E., Neviyarni, \& Ifdil. (2016). EWfektivitas Layanan Informasi dengan Menggunakan Metode Blended Learning untuk Meningjatkan Motivasi Belajar. Psikologi Pendidikan dan Konseling, 2, 84-92.

Hamzah, U. (2007). Teori Motivasi dan Pengukurannya. Jakarta: Bumi Aksara.

Hardini, I., \& Puspitasari, d. (2012). Strategi Pembelajaran Terpadu. Yogyakarta: Familia.

Khotimah, R. H., Radjah, C. L., \& Handarini, D. M. (2016). Hubungan Antara Konsep Diri Akademik, Efikasi Diri Akademik, Harga Diri dan Prokrastinasi Akademik pada Siswa SMP Negeri di Kota Malang. Kajian Bimbingan dan Konseling, 1, 6067.

Komalasari, G., Wahyuni, E., \& Karsih. (2016). Teori dan teknik Konseling. Jakarta: PT Indeks.

Lubis, N. L., \& Hasnida. (2016). Konseling Kelompok. Jakarta: Kencana.

Muslikh, M. (2011). Pendidikan Karakter. Jakarta: PT Bumi Aksara.
Prayitno. (2012). Jenis Layanan dan Kegiatan Konseling. Padang: UNP Profesi Konselor.

Prayitno, \& Amti, E. (1994). Dasar-Dasar Bimbingan dan Konseling. Jakarta: Rineka Cipta.

Rahman, A. A. (2013). Psikologi Sosial Integrasi Pengetahuan Wahyu dan Pengetahuan Empiris. Jakarta: Empirik.

Ridwan. (2008). Belajar Mudah untuk Guru, Karyawan dan Penelitian Pemula. Bandung: Alfabeta.

Sardiman, A. (2012). Interaksi dan Motiasi Belajar Mengajar. Jakarta: Rajawali Pers.

Sobur, A. (2000). Psikologi Umum. Bandung: Pustaka Setia.

Soemanto, W. (1998). Psikologi Pendidikan. Bandung: Rineka Cipta.

Sugiyono. (2004). Statistik Untuk Penelitian. Bandung: Alfabeta.

Sugiyono. (2016). Metode Penelitian. Bandung: Alfabeta.

Surna, I. N., \& Olga D, P. (2014). Psikologi Pendidikan. Jakarta: Erlangga.

Syah, M. (1999). Psikolgi Belajar. Jakarta: Rineka Cipta.

Syah, M. (2012). Psikologi Belajar. Jakarta: Raja Grafindo Persada.

Thalib, S. B. (2010). Psikologi Pendididkan Berbasis Empiris Aplikatif. Jakarta: Kencana.

Tohirin. (2007). Bimbingan dan Konseling di Sekolah dan Madrasah. Jakarta: Raja Grafindo.

Wilis S.S. (2007). Remaja dan Permasalahannya. Bandung: Alfabeta.

Willis S, S. (2007). Konseling Individual Teori dan Praktek. Bandung: Alfabeta 